\title{
Reporting Standards for Statistical Purposes: The Experience of Banco de Portugal ${ }^{1}$
}

\author{
Ana Costa e Silva. Banco de Portugal. Portugal. \\ acsilva@bportugal.pt \\ Margarida Brites Ramos. Banco de Portugal. Portugal. \\ mpramos@bportugal.pt
}

\begin{abstract}
Banco de Portugal (BdP) produces statistics to allow an in-depth understanding of the Portuguese economical situation and to comply with international requirements. With this purpose, the BdP collects high amounts of detailed data from a wide array of institutions, much of which derives from their accounting systems. The quality of this process is improved through the use of standard means of reporting. After providing a brief history of the reporting standards utilized by the BdP over time, we look into how XML allowed a great improvement over preceding standards. Finally, we identify an area within the BdP's reporting standards that needs improvement, that by non-financial corporations, and elaborate on how an XBRL-based reporting standard might best be implemented in Portugal. Given the increasing level of accounting internationalisation, the question can hardly be kept within national boundaries, so our favoured approach is inserted into a European and a Global strategy.
\end{abstract}

Keywords: reporting standards, Official Statistics, XML, XBRL, taxonomy building.

\section{INTRODUCTION}

According to its Organic Law, the Banco de Portugal (BdP) is responsible for centralizing and compiling monetary, financial, exchange and balance of payments statistics, especially in the scope of its cooperation with the European Central Bank (ECB). To perform these tasks, the BdP may request raw data to any private or public entity.

\footnotetext{
1 We would like to thank Josef MacDonald of the International Accounting Standards Board for the discussions on XBRL taxonomy building. The opinions expressed in this article are the responsibility of the authors and do not necessarily reflect those of Banco de Portugal.
} 
From the conceptual point of view, data requested by the $\mathrm{BdP}$ aims at providing information to comply with international standard definitions in statistics. Moreover, the BdP needs to meet highly demanding statistical commitments with, namely, international organizations. In order to fulfil all these requirements, different data reporting systems were implemented, typically according to the type of statistics and the type of data provider.

With the aim of simplifying the task of reporters, the BdP has made some efforts in order to ensure, to the fullest extent possible, that details requested for statistical purposes can be extracted from reporter's internal information systems. As such, subject to the satisfaction of statistical needs, the BdP has been actively involved in minimizing reporting burden.

Based on the BdP's experience, standardization benefits data reporting. A "reporting standard" is any standardised means of communicating to the "statistical entity" raw data relevant for the production of statistics. It involves the content of the data and the technical issue of the data reporting (related to either the format specifications of data or the channel of communication).

Notably there have been improvements in the standards for reporting data to the $\mathrm{BdP}$. The introduction of automatic processes and electronic means of transmission are the most significant ones. Particularly in the field of reporting data for monetary and financial statistics, the BdP has recently experienced a successful change utilizing an $\mathrm{XML}^{2}$-based report that is transmitted through a safe communication channel, the BPnet.

However, there are some systems that have not yet accommodated new technologies. Their business processes need thus to be redesigned or even replaced. There is a clear need to improve the reporting standard for instance of non-financial corporations and a transition to an $\mathrm{XBRL}^{3}$-based reporting system is envisaged as the best solution. The improvement would benefit the reporting corporations, at the level of data reporting, and the BdP, in the treatment of information for statistical purposes.

\footnotetext{
2 eXtensible Markup Language.

3 eXtensible Business Reporting Language.
} 
Notwithstanding, the transition is complicated. Taxonomies have to be developed; the redesign or replacement of existing reporting systems may require participants to make changes to their own systems and processes, which may not come easily or cheaply. Furthermore, successful new systems depend on legislation as well as on the security of the reporting procedures. Nonetheless, the transition can be eased, through the creation of intelligent agents that automatically convert financial statements in diversified formats into XBRL, which is likely to be especially relevant for small and medium sized companies; such agents are already under development in Europe to take advantage of European accounting particularities.

This paper aims at describing the experience of the $\mathrm{BdP}$ in data reporting standards related to the production of statistics. It starts by providing in Section 2 a brief history of the reporting standards used by the BdP. Because it is based on new technologies and innovative on the way of communicating, special focus is made in Section 3 to the most recent reporting system defined by the BdP, which is XML-based and is presently in use for the production of monetary and financial statistics. Sections 3.3.1 and 3.3.2 provide further detail on two features of this new system, respectively the XML-based format files and the BPnet channel used for data communication. Section 4 elaborates on what we consider to be the XBRL scenario that should preferably be built so as to take advantage of all the opportunities XBRL has to offer to the several users of accounting information and to minimize the risks the transition might unfold; aspects such as taxonomy building and automatic instance document generation are described.

\section{A BRIEF HISTORY OF REPORTING STANDARDS IN THE BDP}

In the field of statistics, the term "reporting standard" can be defined as any standardised means of communicating to the "statistical entity" relevant raw data for the production of statistics. In this context, a standard comprises: the syntax (the technical basis of the standard), the content (the type of data necessary to produce statistics) and the channel (the platform through which data transmission occurs). Syntax is roughly analogous to the grammar of a spoken language, while content corresponds to the vocabulary of a spoken language. 
Given the wide range of entities involved in the process of data reporting to the BdP and the diversity of statistics produced, different data reporting systems have been designed and used to meet the extensive statistical commitments of the Bank.

For example, financial institutions are typically approached to provide data for:

- monetary and financial statistics, which is mostly based on the reporting banks' accounting information;

- balance of payments and international investment position statistics, for which banks have to report (either on their own or on behalf of their clients) all settlements made to or received from foreign entities;

- other statistics, for which they have to provide:

(i) positions/flows on securities' accounts,

(ii) interest rates on loans and deposits, and

(iii) credit situation of their clients.

Non-financial corporations are asked to report data for:

- balance of payments and international investment position statistics, either as direct reporters of external settlements made by themselves through accounts abroad (settlements made through resident banking accounts are also requested to a special type of reporters: "General Direct Reporters"), or as direct investors abroad / foreign direct investment entities;

- other statistics on the activity of non-financial corporations, for which corporations basically provide detailed balance sheet and profit and loss account items.

Regarding content, standards defined for data reporting systems are closely linked to the respective output requirements. In fact, contents defined by the $\mathrm{BdP}$ in the field of statistics are aimed at providing information to comply with (i) international standard definitions of statistical concepts and (ii) additional 
demands for both increasing volumes and details on statistics. Statistical standard definitions are broadly made available through statistical manuals produced by international organisations with responsibilities in the field of statistics such as the International Monetary Fund, the United Nations, the Bank for International Settlements and the Organization for Economic Co-operation and Development. These manuals provide the international standards to be met from the output side of the statistical production.

Based on the methodological framework defined by these manuals, these entities and other users of statistics frequently request additional information either on volume or on detail. In the area of the statistical competences of the BdP, the specific requirements of the ECB have significantly increased the statistical work of the Bank and, consequently, that of data providers. It has also implied a continuous adjustment on data reporting contents towards these additional requirements.

The BdP has made some efforts to ensure, to the fullest extent possible, that details requested for statistical purposes can be extracted from the internal information systems of reporters. This task has revealed itself to be difficult for some specific areas of statistics, such as balance of payments/international investment position. The contents of reporting standards in this situation can then be found within the internal information systems of data providers, being the adaptation to statistical concepts, if necessary, performed by the BdP outside the reporting system.

The other components of the standard, the syntax and the channel, are strongly dependent on technological innovation. Based on the main mechanisms used, three different eras can be identified in the history of data transmission to the BdP:

- Until the end of the eighties, data was transmitted to the BdP in paper, by fax or mail. At that time, the effects of the advent of commercial computing, in the beginning of the second part of the XX century, were only felt internally to Portuguese institutions. In the field of statistical production, it made possible for instance the development of better ways for processing and for coding statistical data. Around 25 financial institutions and 700 non-financial enterprises were engaged in the process of data reporting to the BdP in the field of statistics. 
- During the nineties, electronic transmission was gradually introduced by means of discs and magnetic bands, which enabled the automation of data processing. For the banking community, data transmission was further enhanced through a private network managed by the $\mathrm{SIBS}^{4}$ (Sociedade Interbancária de Serviços). Electronic means transported ".txt" files and spreadsheet tables (v.g. "Lotus 123" and "Quattro Pro"). The paper format was mostly used for reporting data by non-financial enterprises. On average, the number of financial institutions that were sending data to the BdP doubled, while the number of non-financial enterprises went up to 14,000 .

- The spread of inexpensive electronic communication enhanced the intensification of electronic reporting of information for statistical purposes. By the turn of the millennium, electronic data reporting to the BdP, in the field of statistics, has become standard practice. Presently, a private network, called BPnet, is also extensively used by the financial community in the communication of statistical data to the BdP (for further details, see Section 3.3.2). In this context, a new technology, XML-based format is being used for monetary and financial reporting (see Section 3.3.1). The transmission of paper has substantially reduced, being only rarely used by non-financial enterprises. Presently, 82 financial institutions and around 16,000 non-financial enterprises are reporting data to the $\mathrm{BdP}$ for statistical purposes.

\section{THE REPORTING SYSTEM OF MONETARY FINANCIAL INSTITUTIONS FOR MONETARY AND FINANCIAL STATISTICS}

We call reporting system the conceptual framework delimited by the answer to the questions "Who / What / When / How do we need in order to produce a given set of statistics?" It encompasses processes related to collecting, transmitting, validating, compiling, analysing, and summarizing data in order to produce the required outputs.

\footnotetext{
4 SIBS was created in 1983, by the Portuguese banking community, with the aim of promoting the automation of routine banking transactions, through the creation of an interbank services network, universal and opened to all participants in the project. SIBS has presently the mission of contributing to the general efficiency of the Portuguese banking system, through the offer of technological solutions to payments and through the supply of other associated services, combining security, effectiveness, comfort and innovation, at the lowest cost possible. Nowadays, the company has thirty-three shareholders, representing almost the totality of retail banking in Portugal.
} 


\subsection{Background and goals}

Monetary financial institutions (MFIs), such as banks, mutual agricultural credit banks, saving banks and money market funds, have extensive relationship with the $\mathrm{BdP}$. In fact, the BdP is the accounting standard setter of MFIs and is the supervisor of their financial stability, which requires MFIs to divulge more data to the BdP than to any other institution. On the other hand, many of the concepts required for Monetary and Financial Statistics do derive from bank accounting items but are not of compulsory or common practice disclosure by MFIs to other users.

With the aim of complying with the statistical requirements of the ECB in the field of (i) consolidated balance sheet of Monetary Financial Institutions (MFIs) and (ii) monetary interest rates, issued in ECB (2001a) and ECB (2001b) respectively, in the beginning of 2003 the BdP designed and implemented a new information system for data reporting by MFIs in the context of monetary and financial statistics.

The new system was also aimed at optimising the statistical system related to monetary and financial statistics, namely by:

- $\quad$ Reducing the reporting burden;

- Including new reporting requirements due to market developments;

- Improving data quality control tools; and

- Adopting a new transmission channel (the BPnet).

\subsection{Legal framework and guidelines}

In addition to ECB (2001a) and ECB (2001b), the ECB has issued other legislative provisions through ECB (2003) concerning certain statistical reporting requirements and procedures to be followed by the National Central Banks in the reporting of statistical information to the ECB in the field of monetary and financial statistics. From the national point of view, the legal framework of the new system was created by BdP (2002a), which concerns MFIs' balance sheet and interest rates statistics.

BdP (2002a) provides the general definition of the new reporting scheme, namely: WHO must report (actual reporting population); WHAT must be reported 
(reporting requirements); WHEN to report (timeliness); and HOW to report (transmission channels, IT specifications). Its Annex goes into details about the reporting scheme, namely the reporting tables, the breakdowns for each reporting dimension, the technical specifications for the transmission files and the minimum standards to be applied by the actual reporting population. Operational details concerning the reporting system were delivered through a Guideline, which focused on data transmission, links between statistical instruments/institutional sectors and the Chart of accounts for the Banking Sector and data quality control rules, among other issues.

\subsection{General characteristics of the reporting system}

Who. Portuguese MFIs are the institutions involved in this type of statistics: the $\mathrm{BdP}$ and the other MFIs. Presently they are, in total, 82 reporting institutions.

The majority of MFIs is requested to report to the BdP on a monthly basis (44 institutions, representing a weight of $98 \%$ of the total assets), while a quarterly reporting frequency is allowed for smaller MFIs (with total assets under 500 million euros).

What/When. Information should be reported in 8 tables, according to detailed requirements, and within three different deadlines:

- The statistical balance sheet, by country and currency, is required until the $10^{\text {th }}$ working day after the reference month;

- Statistics on interest rates must be reported until the $15^{\text {th }}$ working day after the reference month;

- Additional details on the balance sheet are to be sent until the $20^{\text {th }}$ working day.

How. The majority of the information is sent via the Extranet of the BdP, the socalled BPnet, through file transfer facilities. Contingency channels could be Disks and Cds. Email is accepted as a sporadic solution, but it is not recommended.

The file specification used for data transmission is XML. 
Furthermore, the data reported to the BdP must comply with some well-defined minimum requisites ${ }^{5}$ concerning:

a) Transmission; which basically involves reporting within the deadlines and respecting the technical specifications set by the BdP;

b) Accuracy; the statistical information must be correct, i.e. it must fulfils all linear constrains that apply to it;

c) Conceptual compliance; data must be compliant with the definitions and classifications contained in the ECB Regulations;

d) Revisions; data reporting must follow the revision policies set by the ECB and the BdP;

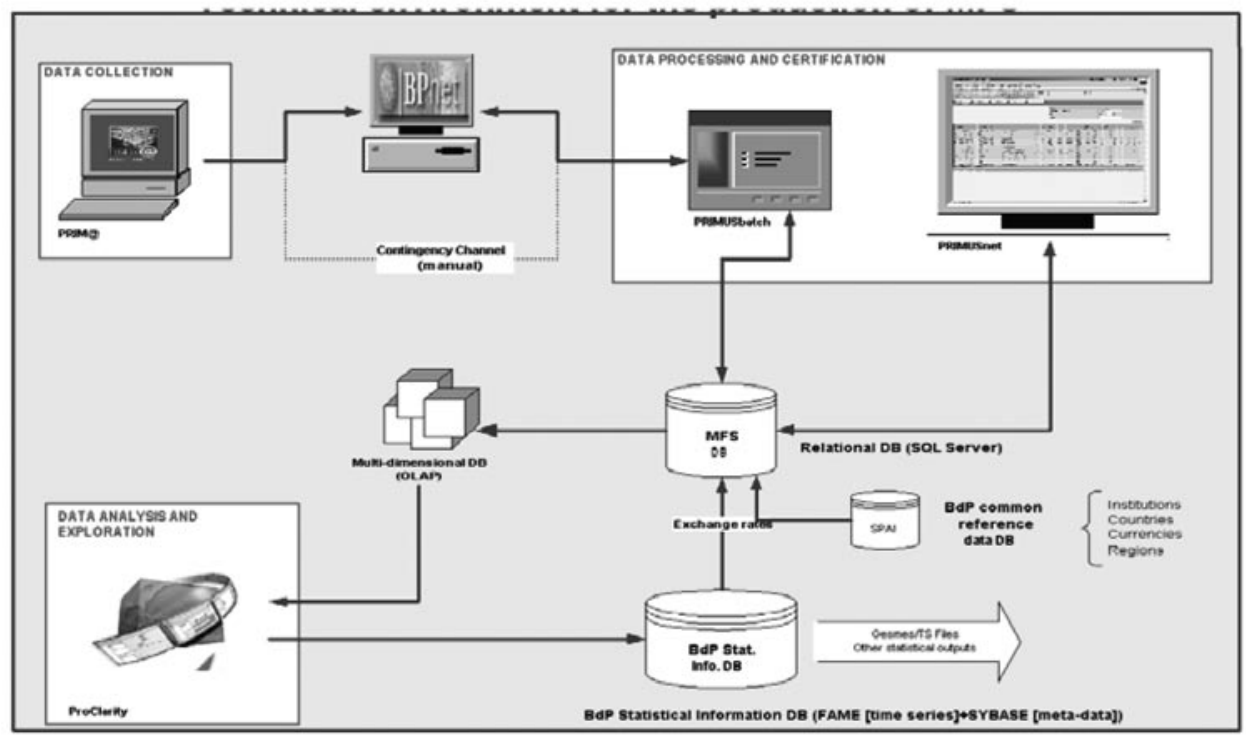

Figure 1. Technical environment for the production of Monetary and Financial Statistics

Any non-compliance with these minimum standards is recorded in an internal database, being the concerned reporting MFI informed of that entry. Under certain circumstances, this may result in an infringement situation.

The system, represented in Figure 1, involves full automation in the field of data transmission and data testing, which is allowed by the use of a diversity of computer applications:

5 As set in ECB (2001a) and ECB (2001b) and transposed to BdP (2002a). 
(i) Data collection: the PRIM@ application is used for collecting data, being distributed to reporters for local installation and voluntary use ${ }^{6}$. It provides for the collection of data either manually or through automatic feed from the records of reporters' internal information systems. Simultaneously, the application allows for testing consistency between tables and/or between different fields within a table. Errors detected by the application cannot avoid entities from reporting, but enable them to identify problems of non-compliance with the minimum level of reporting standards established by the BdP. The application also promotes the creation of the XML file to be reported to the BdP; these are sent to the BdP;

(ii) Certification/Treatment of data: PRIMUSbatch application enables a dialog with the databases of the $\mathrm{BdP}$ and automatically promotes the validation and integration of reported files into the internal databases of the Bank; PRIMUSnet application is used for managing the reported information allowing the consultation, treatment, certification and centralization of all the information;

(iii) Data analysis: OLAP databases and Proclarity, as a front-end application, are used for both analysis and statistical production. At this stage, additional temporal analysis on the main monetary aggregates still enables the identification of problems related to the data transmitted. Institutions are questioned by Email about the problems identified. Supplementary information, available within the Bank, is used for quality control of data reported by MFIs.

Taking into account its general features, the new system still allows the BdP to leverage on highly demanding requirements in the production of statistics, with respect to quality, security, integrity and flexibility. In fact, the standard for reporting data to the BdP in the field of monetary and financial statistics is based on new technologies, and extensively uses Extranet as the communication channel between reporters and the BdP. Moreover, computers are able to understand the reports without human intervention, which contributes to the automatic exchange of information and facilitates communication between the BdP and reporters. The new reporting system has definitely improved efficiency in the statistical production of the Bank.

\footnotetext{
6 Already considered as a common practice of the BdP, computer applications are usually conceived by the Bank and delivered to reporters as a way of contributing to the reduction of reporting burden and, simultaneously, of improving the quality in the statistical production.
} 


\subsubsection{Syntax - XML}

"eXtensible Markup Language (XMLfor short) is a language designed to [...] make information self-describing".

Bosak J., Bray T. (1999)

"A simple, very flexible text format [...] originally designed to meet the challenges of large-scale electronic publishing, XML is also playing an increasingly important role in the exchange of a wide variety of data on the Web and elsewhere".

XML Coordination Group

$\mathrm{XML}$ is not a data format, but a computer language used to describe data formats. This means that it starts by identifying the requirements of the standard data format before designing the standard XML itself that can be used.

In the context of statistics, XML has the potential to overcome two of the most common failings of data reporting standards - that they are either inflexible or too flexible to constitute a standard. Ex ante, XML is highly flexible since it is "eXtensible" - it allows for the creation of new "tags" to describe new and unforeseen message fields. But ex post, XML is rigid - once specifications have been defined, messages can be sent only if precisely formatted. In this respect, XML represents a significant advance in the field of data reporting standards to the BdP.

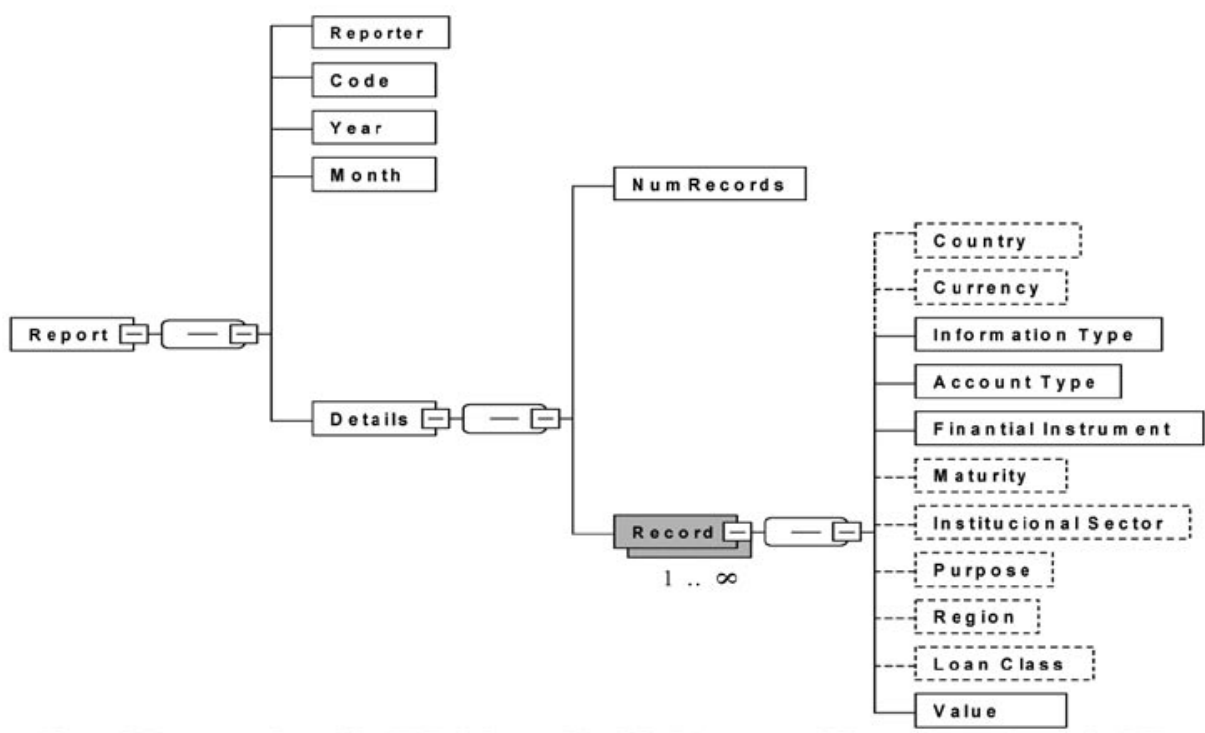

Figure 2. Representation of the XML Schema utilized for Monetary and Financial reporting to the BdP 
In practical terms, the process of creating XML-based standards involves the definition of data fields to conform to particular needs. In the case of data reporting to the BdP for monetary and financial statistics, XML-based format files are requested to comply with an XML Schema, which is "a specification for describing the structure and constraining the contents of XML documents" (Hoffman, 2000). The diagram presented in Figure 2 represents the monetary and financial XML Schema; an extract of its code is provided for illustration purposes in the Annex.

When companies fill in the report using PRIM@, they may have applied some of the consistency checks performed by the BdP; the following step is to create the XML file, which PRIM@ does automatically, and send it to the Bank through the BPnet.

To read an XML-based document, it is crucial to start by testing it against the XML Schema. At this stage, a check is made on obligatory fields, sequences of elements and dimension codes. At the end, a report is produced with the result of the format validation. It corresponds to the first (automatic) report of validation (R1). In the case it does not pass the test, the file returns to the reporter.

The data reported under each element of the XML Schema must respect the details and the format specifications previously defined. These specifications are validated through a new group of tests. Files without inconsistencies are automatically included in the database of the Bank. On the contrary, records with errors originate a second (automatic) report of validation (R2), which is sent to the data reporters. This includes the results of other tests, which aim at assessing the consistency of the data (internally, within each table and between tables; globally, i.e. overall reporting; and temporally, i.e. the evolution).

Both reports (R1 and R2) are transformed into HTML with XSLT ${ }^{7}$, in order to be easily consulted by data providers, and are sent back to reporters via the BPnet.

On the other hand, the importation of data into the internal databases of BdP is also preceded by a XSLT transformation, since the structure of the application does not correspond to the format of the files.

\footnotetext{
7 The XML Stylesheet Language (Transformation) allows users to transform XML documents into virtually any form of output: HTML, XML relatives, other text formats such as GESMES/TS and graphic formats, among others.
} 


\subsubsection{Channel - BPnet, the Extranet of the BdP}

The channel of communication is a non-negligible issue, with implications on the general performance of the system. In the field of statistics, it is important that the channel be compliant with the following security components: availability, confidentiality, integrity, authenticity and non-repudiation. While email cannot be considered a secure platform of communication, the Extranet channel complies with all of the above-mentioned elements.

BPnet is a system of electronic communication, which includes a platform and a pool of services, and is made available and managed by the BdP with the aim of linking the Bank, in the scope of its legal competences, to other entities. This system provides access to several issues managed by the Bank, over a platform that includes a private network between the $\mathrm{BdP}$ and the other participants, an interface web (www.bportugal.net) and mechanisms of security and notification.

It is a flexible system, based on standards available in the market, and it offers the possibility to accommodate future needs in the field of sharing information between participating entities and the BdP. Presently, general facilities are provided for data exchange, namely webmail, file transfer associated with either business areas or specific services, and file transfer between applications. In the field of monetary and financial statistics, for instance, data is reported through file transfer.

It is expected that the benefits of the BPnet will largely exceed the costs of the network. As a matter of fact, the BPnet was able up to now to:

1. reduce direct costs associated with either postal, paper and magnetic supports circulation, and the utilization of the file transfer (which is included in the initial cost of the BPnet);

2. improve quality and simplify the administrative processes related to the communication of diverse information used for supervision purposes, statistical production, central credit registers, restrictions to the use of cheques, and so on;

3. shorten the lags for feedback;

4. enlarge facilities of access and communication with the elements of the Bank belonging to departments involved in providing services through the BPnet; 
5. improve security and ensure confidentiality of the information exchanged;

6. ensure on-line access to the technical support made available by the BdP in order to solve the problems associated with specific services.

In addition to monetary and financial data reporting, other business areas/ services are already making use of the BPnet facilities. In the field of statistics, data reporting performed through the BPnet also involves the following areas: central credit register, balance of payments/international investment position and transactions/positions on securities. For the time being, only financial institutions are participating in the system, thus only this kind of entities is reporting data for statistical purposes through the BPnet.

There is the intention to promote BPnet as the main channel of communication between the BdP and the other participants. By involving other business areas/ services, the BPnet is likely to contribute to increasing standardization and return, and to progressive integration of applications. The effort of enlarging the BPnet to the other statistical areas can therefore be seen as a step forward towards harmonization and automation of statistical reporting.

\section{THE FUTURE REPORTING STANDARD OF NON- FINANCIAL CORPORATIONS FOR OTHER STATISTICAL PRODUCTION}

\subsection{Background}

At the moment, around 16,000 non-financial corporations (NFC) report on a voluntary basis detailed Balance sheet and Profit and Loss account items to the $\mathrm{BdP}$. This information is fundamental to allow an understanding of the evolution of the situation of this economic sector over time. It also serves as the background against which the other statistical areas integrate, since these items allow an overall view on companies' life.

Unlike the privileged relationship the BdP has with MFIs, in the case of NFCs the following constraints present themselves: 
- there is a much larger number of NFCs than there are MFIs and they are a lot more diversified in size and financial soundness;

- the BdP is not the accounting standard setter for NFCs;

- most of the data the BdP needs to collect is GAAP based and is also asked by several different users and data compilers, many of which have the power to demand it by Law, such as the national statistical office (INE), the tax authorities and the commercial registry.

Discussion on which are the best reporting standards could lead us towards the desirability of broad interoperability across data reporting systems. Data reporters frequently express frustration on the lack of harmonization of data reporting standards, which should be as universal as possible, so that there is a common standard for several data collectors. This would, among other consequences, yield a reduction of reporting burden and improve statistical quality, given that data reporters would inherently intensify their cooperation with statistical entities.

Consequently, an XML Schema built by the BdP does not constitute the best solution as the basis for a reporting standard for this type of reporter. As a matter for fact, it would be able to define the characteristics of the information that must be sent to the Bank and the constraints it must satisfy, but other data collectors would develop different schemas, even if they collect mostly the same data. Being that the process for reporters to adapt their information systems to output XML documents is not exactly cost free (in monetary and time terms), the coexistence of different reporting standards utilized by different data collectors is less than efficient.

An advantage XBRL offers is that data collectors and other interested parties can unite in a jurisdiction to define one common XML Schema that encompasses those items of compulsory or common practice disclosure by companies according to the Generally Accepted Accounting Principles (GAAP) of the country. Based on such a Schema, companies can create one single report that they publish on the Web and/or send to all those interested in receiving information from them; these reports can be automatically validated and charged onto data collectors' databases. The productivity gains are obvious. 


\subsection{Concepts and their legal framework}

The vast majority of concepts required by the BdP for statistical purposes can be directly extracted from the Portuguese GAAP (PT-GAAP), specifically they are detailed items of compulsory disclosure in the models of tables that must be published by companies in their financial statements. Classified within a Continental European accounting tradition, the PT-GAAP provides "models of balance sheet and income statement (which) contain detailed elements [...] and companies must disclose in the notes any other material information (which) may be interesting", Ding et al. (2001).

The availability of detailed concepts that are comparable among different companies is a fundamental prerequisite to allow the production of high quality statistics from accounting information. In fact, it is a fundamental prerequisite to allow compilation of any database with detailed information that is comparable among a wide variety of companies. These databases can serve as a valuable tool to support the decisions of a variety of users, including management teams when finding ways to improve their performance, as suggested by Price Waterhouse Cooper (2004), and investors when choosing their investment portfolio. In fact, investors' use of fundamental analysis to evaluate the worth of securities is typically restricted to a small number of cases because it is very costly and time consuming. The possibility of analysing large amounts of detailed financial statement information simultaneously and at small costs would open new avenues for research into fundamental analysis and its relationship with risk diversification.

Even if at the moment only the PT-GAAP is applied in Portugal, from 2005 onwards International Accounting Standards (IAS) will be of compulsory application in the consolidated accounts of all listed companies, European Parliament and Council (2002), and probably in their individual accounts as well, $\mathrm{CNC}^{8}$ (2003). IAS is an Anglo-Saxon oriented GAAP.

Although Ding at al. (2001) remarked that the gap between the two accounting traditions has been gradually reducing and Alexander and Archer (2000) have argued that the similarity between UK and US accounting standards is not that large, the truth is that under GAAPs typically identified as Anglo-Saxon, "firms tend

8 CNC, Comissão de Normalização Contabilística, is the Portuguese accounting standard setter for NFCs. 
to publish relatively simplified balance sheet and income statements and provide afterwards detailed indexed notes", Ding et al. (2001). In such financial statements, comparable accounting detail among different companies is often unavailable. This particular aspect has the following consequences for Statistics:

- a comparison of the data published in the financial statements of different companies in one same country must be made at a much less detailed level of conceptual depth; the detail is similar to what is possible when comparing companies from different countries using different GAAPs. Examples of this are two web sites, Edgar Online's "XBRL Express Dashboard" and Price Waterhouse Cooper's "EdgarScan", which provide a comparison of the data reported by different American companies to the Securities Exchange Commission: most variables for which a comparison is possible are rather aggregate; less aggregated variables are only provided by a few companies; the level of detail provided by all companies is similar to that of the "BACH" international database. Do notice XBRL Express gathers information published using XBRL, which serves to demonstrate how XBRL alone will not solve this problem.

- when detailed data is collected, for example through the use of questionnaires, concepts are especially tailored and the observed entities' information is adjusted through potentially complicated calculations to fit the questionnaire concepts; as an example, consider question 3 of the Quarterly survey of financial statements conducted by Statistics Canada (2002), which asks for the total amount of Inventories but clarifies "Exclude inventory of leased assets of operating lessor - see item 9(a) and capital leased". Under for example the PT GAAP, and typically under the Continental European accounting tradition, this clarification would be a part of the GAAP itself and all users would be aware of it. As such, collection of detailed accounting data under Anglo-Saxon accounting traditions is likely to be more time consuming, costly and error prone.

- given these problems in collecting accounting data, "Anglo-Saxon statisticians" often have to recur to compiling smaller samples and/or use physical rather than accounting data collected from companies; an obvious consequence of using smaller samples in Statistics is that any estimates are more permeable to sampling error. As Greenspan A. (2001) put it about business economics, "greater payoffs will come from more data than more technique (to analyse existing data)". 
- finally, the possibility each company has not to divulge items that are not material for the understanding of its own financial situation (e.g., IAS1\$29-31) has as consequence that the non-disclosure of an item by a company does not mean it equals zero (as it would under Continental European traditions). The magnitude of the difference to zero will not be the same for different companies, as materiality is assessed in relative terms. For Statistics, the addition of all of these non-zero items for all companies in a country is certainly a material amount and creates a new source of error that adds to for instance the already existing sampling error. This is more serious if companies not only do not divulge, but also are not able to isolate Economically/Statistically relevant items in their information systems.

With the purpose of minimizing the incomparability derived from different companies in the country applying different GAAPs, CNC is in the process of adapting the PT-GAAP to bring it closer to IAS and of proposing a code of accounts and a reporting model to be applied compulsorily by all unlisted corporations and voluntary by those subject to IAS. On the other hand, to minimize the difficulties created by companies deciding unilaterally which items to disclose or not, the Portuguese accounting standard setter for NFCs intend to demand compulsory disclosure of some national items as well, CNC (2003).

\subsection{Syntax - XBRL}

"A tool to make reporting more comparable (that) greatly improves: Reliability; Understandability; Comparability".

Ramin K. (2001)

"XBRL can help us model GAAPs to produce GAAP consistent electronically tagged data".

Teixeira A. et al (2003)

$\mathrm{XBRL}$ is an extension of XML to the specific field of business reporting. Like XML, XBRL has the advantage of being highly flexible ex ante, since it is "eXtensible", i.e. it allows for the creation of new "tags" to describe unforeseen message fields; but ex post, it is rigid - once specifications have been defined, messages can be sent only if precisely formatted. This aspect is very important in the context of Statistics.

Originating from an Anglo-Saxon environment, XBRL is in practical terms, the format those GAAPs do not contemplate. XBRL financial statements created by companies (the so-called instance documents) are validated against the XBRL 
taxonomy that applies to the GAAP the statements are published under. Creating these XBRL taxonomies to adapt to national specific GAAPs is the job of jurisdictions. XBRL taxonomies comprise (among other optional components):

\begin{tabular}{|c|c|}
\hline XBRL Taxonomy components & $\begin{array}{l}\text { e.g. IASCF \& XBRL } \\
\text { International (2004) }\end{array}$ \\
\hline $\begin{array}{l}\text { - a set of elements that univocally describe a set of publishable } \\
\text { concepts; these are intended to be used when preparing XBRL } \\
\text { instance documents; }\end{array}$ & IssuedCapital \\
\hline \multicolumn{2}{|l|}{ - a set of linkbases that characterize each element: } \\
\hline $\begin{array}{l}\text { - the definitions that apply to it, which may encompass } \\
\text { non-arithmetic complex relations with different items } \\
\text { (in the definition linkbase); }\end{array}$ & \\
\hline $\begin{array}{l}\text { - the arithmetic constraints that relate it to other items (the } \\
\text { calculation linkbase); }\end{array}$ & $\begin{array}{l}\text { Adds into } \\
\text { EquityParentTotal }\end{array}$ \\
\hline $\begin{array}{l}\text { - the position within the statement the item is expected to } \\
\text { appear in (presentation linkbase); }\end{array}$ & $\begin{array}{l}\text { Appears as credit in } \\
\text { the balance sheet, after } \\
\text { EquityPresentation }\end{array}$ \\
\hline $\begin{array}{l}\text { - the label that describes the item (label linkbase); several } \\
\text { labels in different languages or even dialects can be } \\
\text { defined for a given item; this allows elements to be } \\
\text { translated automatically into different languages, which } \\
\text { is an interesting aspect for a small open economy such as } \\
\text { the Portuguese; }\end{array}$ & EN: Issued Capital \\
\hline $\begin{array}{l}\text { - the relevant legislation that applies to the item (the } \\
\text { reference linkbase); it is this relevant legislation that } \\
\text { defines the valuation rules that apply to the element, } \\
\text { which may differ from GAAP to GAAP. }\end{array}$ & $\begin{array}{l}\text { - } \quad \text { I A S } 1 \S 73 \mathrm{e}, \\
\text { IAS } 1 \S 72\end{array}$ \\
\hline
\end{tabular}

Table 1. Components of XBRL taxonomies.

As such, the taxonomy contains all the necessary information to make clear to all its users what each element is expected to be. Teixeira A. et al. (2003) have argued that element Ids (in our example, IssuedCapital) rather than be similar to one of its possible labels, should be an alphanumerical code void of meaning in itself. That way a change in labels in the future would not require a change in all the taxonomies that built on it. 


\subsubsection{Taxonomy building}

\subsubsection{Building taxonomies in Europe - the case of Portugal}

Given the coexistence in Portugal, as in many other European countries, of two distinct accounting standards, the PT-GAAP and IAS, after 2005, it would make little sense to build two unrelated taxonomies for each. In our opinion, a Portuguese taxonomy should preferably utilize the same elements that have already been created for IAS-XBRL or other taxonomies and add to them only those that are totally Portuguese specific; a distinct set of linkbases would characterize the elements according to the PT-GAAP, e.g. because different GAAPs aggregate elements differently, the calculation linkbase would specify how the elements aggregate into each other under the PT-GAAP.

The decision of which PT-GAAP elements to identify using IAS element IDs should be based on the notion of equivalency, defined by Teixeira A. et al. (2003): "Equivalency (between elements defined under different GAAPs) can be viewed, without any loss of generality, as being a function of which elements are required to be disclosed (disclosure equivalency) and how they are measured (absolute equivalency)". Disclosure equivalency is required to assign the same element ID to concepts under different GAAPs. The GAAP specific reference and calculation linkbases can clarify to users how close to absolute equivalency the elements actually are. As such, in the example provided in the previous section, Issued Capital is a required disclosure under the PT-GAAP; it is disclosure equivalent to the elements referenced under IAS $1 \S 72$ and $1 \S 73$ e and EEC (1978) 4th Directive article $9 \mathrm{~A} \mathrm{I}$ and $10 \mathrm{~L} \mathrm{I}$; they should have the same IDs.

This approach to taxonomy extension building was called by Teixeira et al. (2003) "Integrated extension building". They suggest each new taxonomy should be built through addition, deletion or modification of the elements of an existing taxonomy, its Anchor, which in the Portuguese case would be the XBRL-IAS taxonomy. They claim such an approach not only allows deriving how similar each GAAP is to IAS in terms of disclosure, but also how two GAAPs extended from IAS relate to each other.

However, most European GAAPs contain for example the concept "Other external charges", which does not exist under IAS but is often a material operational 
cost item. Under Teixeira et al.'s (2003) approach to taxonomy extension, all European jurisdictions would create a different Element-ID for this element. On the other hand, several European GAAPs, including the Portuguese, consider under Extraordinary loss (gain) an amount which is conceptually close to impairment loss (impairment reversal). While some jurisdictions might think the two items are similar enough to be considered disclosure wise equivalent, others might choose otherwise, so similar situations might not be treated equally by different jurisdictions. Finally, as the number of jurisdictional taxonomies built using as Anchor IAS-XBRL increases, the group of elements that are common to all decreases and with it our ability to compare disclosure habits of different GAAPs with XBRL.

As such, the Portuguese taxonomy would preferably:

- take all elements of the IAS-XBRL taxonomy (none would be removed since some Portuguese companies have to apply IAS and the remaining may want to make similar disclosures in certain areas);

- add to them elements that are of compulsory or common practice disclosure according to the Forth and Seventh Directive; preferably these elements' IDs would be harmonized at least on a European level;

- add them with elements that are of compulsory or common practice disclosure according to the PT-GAAP, e.g. Prestações suplementares.

Figure 3 represents the taxonomy family tree that would exist in Europe if this approach were followed.

\subsubsection{Building internationally communicating taxonomies}

The problem of disjoint extension creation in different jurisdictions obviously affects all new jurisdictions, including non-European ones. Consequently, even under an "Integrated extension building" Extraordinary profit and loss, which does not exist under the revised IAS, would potentially receive as many different element IDs as there are jurisdictions. 


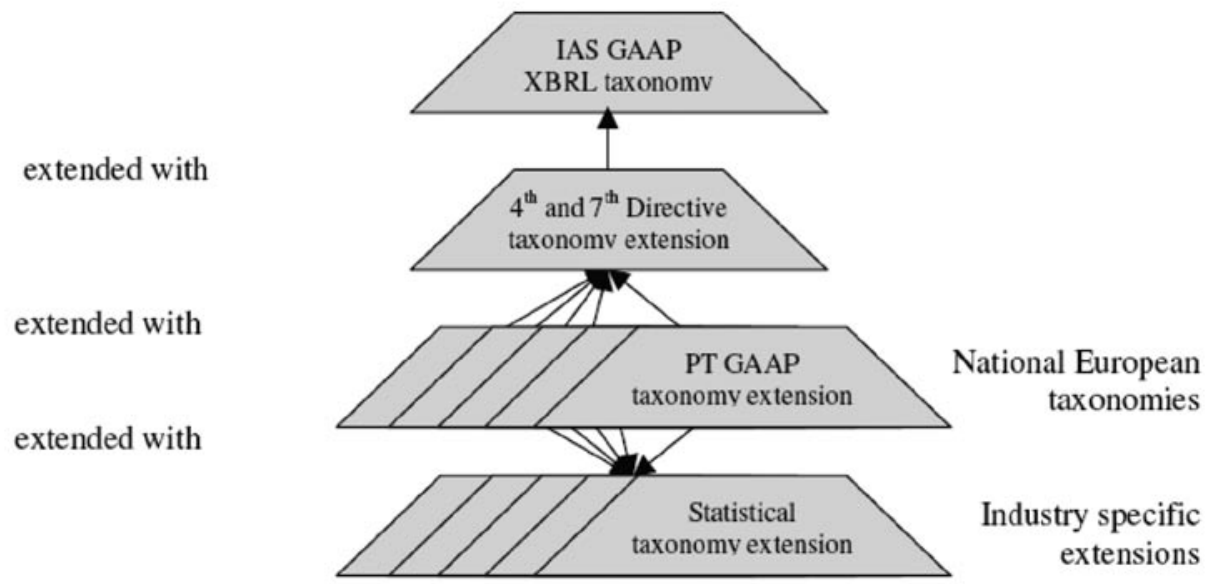

Figure 3. Proposed Family tree of taxonomies applicable in Europe

In the following quotation, one could replace the word "company" by "jurisdiction".

"If every company were free to develop its own labels for its XML tags, then the searching for financial information would be only marginally improved".

(Debreceny, 2001)

What we suggest is that instead of using as Anchor a taxonomy created by only one jurisdiction, the Anchor could be the reunion of all the elements created by all approved taxonomies, one big pull of publishable accounting concepts and their IDs. To facilitate the interpretation of each element in the pull, each would refer the taxonomy that first created it. New jurisdictions would be able to reach into the pull for the elements that they require and combine them using their national specific linkbases. The XBRL Consortium would ensure that different taxonomies do not create new elements for similar concepts when one is already available. We call this approach to taxonomy development a "Fully Integrated Extension Building".

Such an Anchor would be very big in size; IASCF \& XBRL International (2004) alone contains over 3000 elements. Taxonomy building software developers can make the resulting dimension of the Anchor tractable by users. For example, the time order of the approval of each jurisdictional taxonomy by the XBRL Consortium could stipulate a hierarchy for the taxonomies created by different jurisdictions; 
items could be ordered according to the presentational linkbases of higher up taxonomies (elements could eventually be repeated in different places); users could visualise higher elements first and drill-down or up the hierarchical tree. Teixeira et al. (2003) also suggested the possibility of querying the Anchor for topics, for example "visualize all elements that refer to Property Plant and Equipment".

National calculation linkbases can be seen as a tree of accounting concepts. It would be interesting if the Anchor characterized each element in terms of the number of taxonomies that mention it and the number of taxonomies it is a leaf (and not a knot) of.

\subsubsection{Some advantages of integrating taxonomies}

Our basic belief is that if different taxonomies share, to the maximum extent possible, the same basic elements and identify these with the same element IDs, this will facilitate the adoption by companies of comparable accounting detail in their information systems to allow the quantification of a greater part of the common taxonomy elements. This is all the more likely for:

- multinational companies, who at the moment calculate non-integrated accounting detail under several different GAAPs to comply with national specific disclosure requirements and then make complicated reconciliation between them for consolidation purposes;

- international business software companies, who may be interested in organizing the information systems they build and sell to allow the calculation of a bigger part of these internationally common elements, especially of those that are leafs in a significant number of taxonomies.

On the other hand, a "Fully integrated extension building" approach would contribute to effectively reduce one of the two aspects that make accounting concepts internationally incomparable, element positioning, i.e. the way they are aggregated. In fact,

"As long as the data captured in an entity's information system are sufficient to apply the requirements of a specified GAAP the data can be shaped in any way. 
As a simple example, interest relating to borrowings on the construction of an asset might be required to be capitalised in one jurisdiction and expensed in another. An appropriately specified database can capture sufficient information about the transaction that will allow the data to be shaped in both ways in subsequent reports. Hence, multi-GAAP reporting from one source is possible. XBRL facilitates this process."

Teixeira A. (2004)

This being true, only the second source of international incomparability would remain for accounting standard setters to solve, valuation differences. Given the current trend of internationalisation that is sweeping through accounting practices around the world, it can be foreseen that in time standard setters will tend to harmonize valuation policies and minimize discretion. XBRL taxonomies can now already be built taking into account this potential opportunity (and maybe even facilitating it, as current differences and similarities between GAAPs would be easier to catalogue by standard setters), in such a way that as valuation rules harmonize no extra costs have to be faced in renaming all XBRL elements to achieve full international accounting comparability.

It should be noticed that several European countries plus Japan and the United States already publish aggregate data on non-financial corporations that solves the first source of international incomparability: currently, the European Commission's "BACH database" allows users to compare the evolution of several financial indicators in different countries, by sector of activity and company size. Users have to bare in mind the following restriction: "while trend comparisons can [...] certainly be made, comparisons in terms of level are more difficult $[\ldots]$ and call for a sound a priori knowledge of the accounting and financial environment of each country", European Commission II (2001).

Bearing that restriction in mind, under an integrated XBRL environment, investors or lenders would be able to compare the evolutions of key indicators over time among many different companies and utilize the findings for risk management purposes (notice that a good part of the suppliers of data to $\mathrm{BACH}$ database collect it for credit risk management).

\subsubsection{Instance document creation}

When creating instance-document, companies would resort to the XBRL namespace concept, whereby a small code would be added to each element in order to 
identify the GAAP and linkbases that apply to it. "Namespaces are [...] a very powerful feature [...] (that) basically solve the problem of two groups creating different taxonomies but using the same name within that taxonomy", Hoffman (2000). In the example above, the element "IssuedCapital" would in a Portuguese financial statement become, for example, "pt:IssuedCapital".

However, it must be stated that the process to full XBRL adoption by companies is complicated. The redesign or replacement of existing reporting systems may require participants to make changes to their own systems and processes, which may not come easily or cheaply. This is particularly relevant in the case of small and medium sized enterprises, who have a smaller part of the announced benefits of implementing XBRL, in terms of more efficient, less costly (Balwin A. and Trinkle B. (2004)) and more transparent (Hodge et al. (2002)) financial reporting. Furthermore, apart from standardization, successful new systems still depend on legislation as well as on the security of the reporting procedures.

To address these potential hazards, an intelligent agent is being built that allows automatic conversion of parts of financial statements in diversified formats into XBRL, as explained in Silva et al. (2004). The agent relies on the structure of XBRL jurisdictional taxonomies as a plug-in source of context-specific accounting knowledge. This aspect allows it to easily adapt to different GAAPs and take full advantage of the accounting particularities of the Continental European accounting approach to extract detailed comparable accounting items from many different companies' financial statements. In this particular aspect it is fundamentally different from its American counterparts, Price Waterhouses's EdgarScan and Ernst \& Young's \& University of Kansas's Fraank.

\subsection{Channel}

Different solutions are being considered as an appropriate channel for companies reporting to the $\mathrm{BdP}$ in XBRL. While at the moment, diskettes are still somewhat used by this type of reporter, email and upload on the Internet are increasingly popular and more in line with XBRL reporting. The extension of BPnet to this type of user is envisaged as an interesting prospect. 


\section{CONCLUSIONS}

In this paper we have described how harmonizing data reporting standards contributes to improving the quality of the analyses that can be made on the gathered data; we have also identified what we consider to be the three basic components of a data reporting standard: concept, syntax and channel.

The development of common reporting standards based on the most advanced technologies is essential to move towards automated processing of statistical data, with the resulting improvement in quality and productivity. This automation is expected to bring significant efficiency and quality gains, as well as a reduction of costs. In this sense, we have seen how XML has had a major impact on the collection of data for compilation of monetary and financial statistics within the $\mathrm{BdP}$, having effectively contributed to reducing reporting burden and easing the validation of the quality of reports, which contributed to improve efficiency not only within the BdP, as a data collector, but also within data reporters.

We have also looked at the financial reporting of Non-financial corporations from an unusual perspective in Literature, that of an entity that needs to collect detailed data that is highly comparable among different companies. The need to simultaneously analyse financial information of different companies has not been a priority of accounting standard setters internationally, probably because the feasibility to analyse great volumes of financial data is much more recent than accounting standards, but we hope to have shown how it can be beneficial to a wide diversity of users around the Globe, including investors when choosing an investment portfolio.

Finally, we have described how we believe a universally accepted reporting standard for non-financial corporations utilizing the PT-GAAP can, based on XBRL, be implemented. With the current level of internationalisation that is sweeping through accounting in Europe and around the Globe, the question can hardly be dissociated from the development of XBRL internationally. We have proposed approaches to building internationally comparable taxonomy extensions and to generating instance documents. 


\section{REFERENCES}

ALEXANDER, D; ARCHER, S. (2000): "On the Myth of "Anglo-Saxon" Financial Accounting", The International Journal of Accounting, vol. 35, n. 4, pp. 539-557.

BALDWIN, A.; TRINKLE B. (2004): "The impact of XBRL in 2010, a Delphi investigation", Paper presented at the 2004 Annual Meeting of the American Accounting Association, Florida, USA.

BdP, Banco de Portugal (2002a): "Instruction $\mathrm{n}^{\circ} 19 / 2002$ concerning the monetary and financial data reporting system to the BdP", Boletim Oficial do Banco de Portugal, Portugal.

BdP, Banco de Portugal (2002b): "Instruction n. 30/2002 concerning the BPnet", Boletim Oficial do Banco de Portugal, Portugal.

BOSAK J.; BRAY, T. (1999): "XML and the Second-Generation Web - The combination of hypertext and a global Internet started a revolution. A new ingredient, XML, is poised to finish the job", Scientific American.com, May 1999.

CNC, Comissão de Normalização Contabilística (2003): Projecto de linhas de orientação para um novo modelo de normalização contabilística. Portugal. www. cnc.min-financas.pt/

DEBRECENY, R.; GRAY, G.A. (2001): “The production and use of semantically rich accounting reports on the internet: XML and XBRL", International Journal of Accounting Information Systems, n.2., pp.47-74, USA.

DING, Y.; STOLOWY, H.; TENENHAUS, M. (2001): "The Internationalization of Financial Statements Presentation: an Empirical Study of French Groups". Paper presented at the 24th Annual Congress of the European Accounting Association, Athens, Greece.

ECB, EUROPEAN CENTRAL BANK (2001a): "Regulation (EC) No 2423/2001 of the ECB of 22 November 2001 concerning the consolidated balance sheet of the monetary financial institutions sector (ECB/2001/13)", Official Journal of the European Communities, L 333, 17/12/2001, pp.1, Belgium. 
ECB, EUROPEAN CENTRAL BANK (2001b): "Regulation (EC) No 63/2002 of the ECB of 20 December 2001 concerning statistics on interest rates applied by monetary financial institutions to deposits and loans vis-à-vis households and non-financial corporations (ECB/2001/18)", Official Journal of the European Communities L 10, 12/01/2002, pp.24, Belgium.

ECB, EUROPEAN CENTRAL BANK (2003): "Guideline of the ECB of 6 February 2003 concerning certain statistical reporting requirements of the ECB and the procedures for reporting by the national central banks of statistical information in the field of money and banking statistics (ECB/2003/2)", Official Journal of the European Communities, L 241, 26/09/2003, pp.1, Belgium.

EDGAR ONLINE: XBRL Express Dashboard. USA. www.edgar-online.com/

EEC, EUROPEAN ECONOMIC COMMUNITY (1978): "4th Directive on the annual accounts of certain types of companies n ${ }^{\circ} 78 / 660 / E E C$ of 25 July 1978", Official Journal of the European Communities, L 222, 14/08/1978, pp.11-31, Belgium.

EEC, EUROPEAN ECONOMIC COMMUNITY (1983): "7th Directive on consolidated accounts of companies n ${ }^{\circ} 83 / 349 /$ EEC of 13 June 1983", Official Journal of the European Communities, L 193, 18/07/1983, pp.1-17, Belgium.

EEC, EUROPEAN COMMISSION DG II: Bank for the Accounts of Companies Harmonised. Directorate General for Economic and Financial Affairs, European Committee of Central Balance Sheet Data Offices, Belgium.

EUROPEAN COMMISSION DG II (2001): BACH guide for data users. Directorate General for Economic and Financial Affairs, European Committee of Central Balance Sheet Data Offices, Belgium.

EUROPEAN PARLIAMENT AND COUNCIL (2002): “Regulation (EC)1606/2002 of the European Parliament and of the Council on 19 July 2002 on the application of international accounting standards", Official Journal of the European Communities, L 243, 11/09/2002, pp. 1-4, Belgium.

ERNST \& YOUNG; UNIVERSITY OF KANSAS: Fraank. http://fraank.eycarat. ukans.edu/cgi-bin/10k/10k.htm, USA. 
GREENSPAN, A. (2001): Speech to the National Association of Business Economics, NABE Policy Conference, USA.

IASCF; XBRL International (2004): “International Financial Reporting Standards (IFRS) General Purpose Financial Reporting for Profit-Oriented Entities (GP), 2004-06-15, Exposure Draft", UK.

HODGE, F.; KENNEDY, J.J.; MAINES, L.A. (2002): Recognition versus Disclosure in Financial Statements: Does Search-facilitating Technology Improve Transparency?. Research report. School of Business, University of Washington, USA.

HOFFMAN, C. (2000): XBRL taxonomy creation - training class, USA.

PRICE WATERHOUSE COOPERS: Edgarscan. Technology Centre, USA. http:// edgarscan.pwcglobal.com/servlets/edgarscan

PRICE WATERHOUSE COOPERS (2004): AMMBIT-Advanced Middle Market Business Intelligence Tool - Improve cash flow by managing accounts payable. http://www.ammbit.com

RAMIN, K. (2001), "Intangibles and the New Business Reporting Language (XBRL): An Update from the IASB", presentation at Ferrara International Research Seminar on Intangibles and Intellectual Capital, Italy.

SDMX INITIATIVE: various working documents developed under the SDMX projects. http://www.sdmx.org

SILVA, A.C.; JORGE, A.; TORGO, L. (2004): Design of an end-to-end method to extract information from tables, under submission, Portugal. Available at http:// www.niaad.liacc.up.pt/ amjorge/docs/tablesmm.pdf.

STATISTICS CANADA (2002): Quarterly survey of financial statements". Industrial organization and finance division. Canada.

TEIXEIRA, A.; HOFFMAN, C.; MACDONALD J. (2003): Taxonomy mapping - the process of creating extension taxonomies. XBRL discussion papers. http:// www.iasb.org

TEIXEIRA, A. (2004): "Implications of XBRL". Conferenz.co.nz. New Zealand. http://www.conferenz.co.nz/2004/library/reading_room.html. 
VAN den BERGH P. (2002): "Common open standards for the exchange and sharing of socio-economic data and metadata: the SDMX Initiative". Paper presented at the Irvin Fisher Committee Conference on Challenges to Central Bank Statistical Activities, Switzerland.

XML Coordination Group. W3C Working Group. http://www.w3.org/XML/.

APPENDIX: extract of the XML Schema utilized for the Monetary and Financial reporting to the $\mathrm{BdP}$

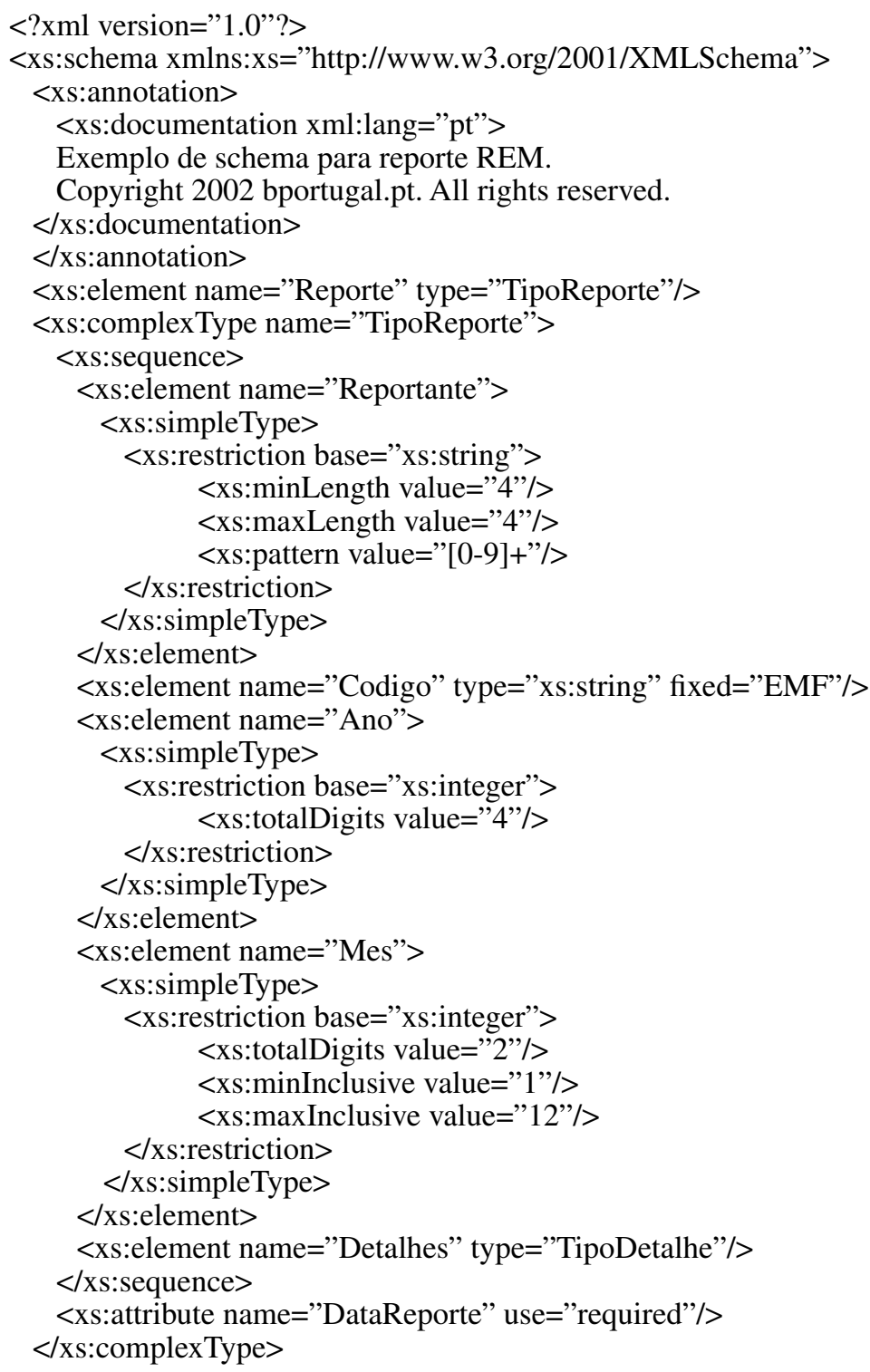

